\title{
NELFINAVIR, EFAVIRENZ, OR BOTH AFTER THE FAILURE OF NUCLEOSIDE TREATMENT OF HIV INFECTION
}

\author{
Mary A. Albrecht, M.D., Ronald J. Bosch, Ph.D., Scott M. Hammer, M.D., Song-Heng Liou, M.A., \\ Harold Kessler, M.D., Michael F. Para, M.D., Joseph Eron, M.D., Hernan Valdez, M.D., \\ MarJorie Dehlinger, D.N.Sc., AND DAVID A. Katzenstein, M.D., \\ for the AIDS Clinical Trials Group 364 Study Team
}

\begin{abstract}
Background The optimal antiretroviral treatment for patients who have human immunodeficiency virus (HIV) viremia despite treatment with nucleoside reverse-transcriptase inhibitors (nucleoside analogues) remains uncertain. We studied treatment with regimens that combined two nucleoside analogues, at least one of which was new, with the protease inhibitor nelfinavir, the nonnucleoside reverse-transcriptase inhibitor efavirenz, or both.

Methods The study included 195 patients who had been treated with nucleoside analogues only, and had a plasma HIV type 1 (HIV-1) RNA level of at least 500 copies per milliliter. Patients were randomly assigned to receive, in addition to two nucleoside analogues, nelfinavir, efavirenz, or nelfinavir plus efavirenz. The primary end point was a plasma HIV-1 RNA level of less than 500 copies per milliliter at week 16. A secondary end point was the composite of the HIV-1 RNA levels measured at weeks 40 and 48 .

Results At week 16 and at weeks 40 and 48, the proportions of patients in whom a plasma HIV-1 RNA level of less than 500 copies per milliliter was achieved were, respectively, 81 percent and 74 percent in the nelfinavir-plus-efavirenz group, 69 percent and 60 percent in the efavirenz group, and 64 percent and 35 percent in the nelfinavir group. Quadruple therapy resulted in a higher rate of viral suppression in both the short term $(P=0.03)$ and the long term $(P=0.001)$ than did triple therapy with nelfinavir. Triple therapy with efavirenz conferred a higher rate of long-term suppression than triple therapy with nelfinavir $(\mathrm{P}=$ 0.004). Quadruple therapy also achieved a higher rate of virologic suppression than triple therapy with efavirenz $(\mathrm{P}=0.008)$.

Conclusions In HIV-infected patients previously treated with nucleoside analogues, treatment with nelfinavir plus efavirenz and at least one new nucleoside analogue achieves a higher rate of viral suppression than do regimens with nucleoside analogues and nelfinavir or efavirenz alone. (N Engl J Med 2001;345: 398-407.)
\end{abstract}

Copyright $\odot 2001$ Massachusetts Medical Society.

I $\mathrm{N}$ patients infected with the human immunodeficiency virus (HIV), whether or not they have previously taken nucleoside reverse-transcriptase inhibitors (nucleoside analogues), regimens containing HIV-protease inhibitors ${ }^{1-4}$ have been shown to suppress viral replication better than therapy with two nucleoside analogues. ${ }^{5-7}$ Therapy with nonnucleoside reverse-transcriptase inhibitors ${ }^{8-10}$ can achieve durable suppression in patients who have not yet been treated with nucleoside analogues.

Although response rates to protease inhibitors or nonnucleoside reverse-transcriptase inhibitors of 70 to 90 percent have been described in such patients, the response rates are lower ( 45 to 80 percent) in patients who have already been treated with nucleoside analogues.4,11 The optimal use of new antiretroviral treatments for the latter group of patients is not well defined. We undertook a trial to evaluate whether a protease inhibitor, nelfinavir, or a nonnucleoside reverse-transcriptase inhibitor, efavirenz, or the combination of the two, along with two nucleoside analogues, at least one of which was new to the patient, would lead to the greatest reduction in the plasma viral load in patients who had undergone extensive previous treatment with nucleoside analogues.

\section{METHODS}

\section{Study Design and Patients}

The AIDS Clinical Trials Group (ACTG) $302^{12}$ and ACTG $303^{13}$ "rollover" studies that followed the ACTG 175 study 14 were randomized, partially blinded trials in which regimens of new nucleoside analogues or stavudine monotherapy were evaluated in patients who had received zidovudine alone, zidovudine plus didanosine, zidovudine plus zalcitabine, or didanosine monotherapy while participating in the ACTG 175 study (Fig. 1). In the year before their entry into the current study, patients who had received therapy with nucleoside analogues exclusively for a median of 5.6 years continued to receive the nucleoside-analogue regimens to which they had been assigned in ACTG 302 or 303 .

The ACTG 364 study was a phase 2 , randomized, multicenter, partially double-blind, three-group trial that compared nelfinavir, efavirenz, and nelfinavir plus efavirenz, in combination with openlabel dual-nucleoside therapy, in patients with plasma HIV RNA levels of at least 500 copies per milliliter at screening. The randomization was stratified according to the treatment patients had received in the ACTG 302 or 303 study. The primary outcome measure, the short-term change in the plasma levels of HIV type 1 (HIV-1) RNA, was evaluated in terms of the proportion of pa-

From the Beth Israel Deaconess Medical Center and Harvard Medical School, Boston (M.A.A.); the Department of Biostatistics, Harvard School of Public Health, Boston (R.J.B., S.-H.L.); Columbia University College of Physicians and Surgeons, New York (S.M.H.); Rush Medical College, Chicago (H.K.); Ohio State University College of Medicine and Public Health, Columbus (M.F.P.); the University of North Carolina, Chapel Hill (J.E.); Case Western Reserve University School of Medicine, Cleveland (H.V.); the HIV Research Branch, Division of AIDS, National Institute of Allergy and Infectious Diseases, Bethesda, Md. (M.D.); and Stanford University Medical Center, Stanford, Calif. (D.A.K.). Address reprint requests to Dr. Albrecht at the Division of Infectious Diseases, Beth Israel Deaconess Medical Center, l Deaconess Rd., Kennedy-6, Boston, MA 02215. 


\begin{tabular}{|c|c|c|c|c|c|c|}
\hline \multicolumn{2}{|c|}{$\begin{array}{l}\text { ACTG } 175 \text { Study } \\
\quad(N=195)\end{array}$} & & \multicolumn{3}{|c|}{$\begin{array}{l}\text { ACTG } 302 \text { and } 303 \text { Studies } \\
\qquad(N=85) /(N=110)\end{array}$} & $\begin{array}{l}\text { ACTG } 364 \text { Study } \\
\qquad(N=195)\end{array}$ \\
\hline $\begin{array}{l}\text { Nucleoside } \\
\text { Analogue }\end{array}$ & $\begin{array}{c}\text { No. of } \\
\text { Patients (\%) }\end{array}$ & & $\begin{array}{l}\text { Nucleoside- } \\
\text { Analogue } \\
\text { Regimens }\end{array}$ & Trials & $\begin{array}{l}\text { No. of } \\
\text { Patients } \\
(\%)\end{array}$ & NFV+ nucleoside analogues \\
\hline $\begin{array}{l}\text { ZDV } \\
\text { ddl } \\
\text { ZDV plus ddl } \\
\text { ZDV plus ddC }\end{array}$ & $\begin{array}{l}34(17) \\
56(29) \\
60(31) \\
45(23)\end{array}$ & & $\begin{array}{l}\mathrm{d} 4 \mathrm{~T} \\
\text { ZDV and 3TC } \\
\text { ZDV and ddl } \\
\text { ZDV and ddC } \\
\text { ZDV, ddC, } \\
\text { and 3TC } \\
\text { ZDV, ddl, } \\
\text { and 3TC }\end{array}$ & $\begin{array}{c}302 \\
302,303 \\
302,303 \\
303 \\
303 \\
302,303\end{array}$ & $\begin{array}{l}10 \quad(5) \\
57(29) \\
41(21) \\
14 \quad(7) \\
21(11) \\
52(27)\end{array}$ & $\begin{array}{c}\mathrm{NFV}+\mathrm{EFV}+\text { nucleoside } \\
\text { analogues }\end{array}$ \\
\hline \multicolumn{2}{|c|}{$\begin{array}{l}\text { Randomized, double-blind trial } \\
\text { Enrollment, } 12 / 91-10 / 92 ; \\
\text { duration, } 1991-1995 \\
\text { Number of randomized patients: } \\
2467 \\
\text { Eligibility criteria: } \\
\text { CD4 cell count: } 200-500 \text { cells } / \mathrm{mm}^{3} \\
\text { No AIDS-defining event (minimal } \\
\text { Kaposi's sarcoma allowed) } \\
\text { Previous exposure to a nucleo- } \\
\text { side analogue (ZDV or ddl) } \\
\text { allowed }\end{array}$} & & \multicolumn{3}{|c|}{$\begin{array}{l}\text { Randomized, partially double-blind } \\
\text { trials (open-label ZDV) } \\
\text { Enrollment, 10/95-1/96; } \\
\text { duration, 1995-1997 } \\
\text { Number of randomized patients: } \\
325 \text { in ACTG 303; } 229 \text { in ACTG } 302 \\
\text { Stratified according to nucleoside } \\
\text { analogues received in ACTG } 175 \\
\text { Eligibility criteria: } \\
\text { Maintenance of original ACTG } 175 \\
\text { nucleoside-analogue therapy; } \\
\text { or crossover to combination } \\
\text { nucleoside-analogue therapy } \\
\text { during ACTG 175 for AIDS- } \\
\text { defining event }\end{array}$} & $\begin{array}{l}1 \text { or } 2 \text { new nucleoside ana- } \\
\text { logues assigned as part of } \\
\text { dual-nucleoside components: } \\
\text { d4T plus ddl } \\
\text { d4T plus 3TC } \\
\text { ddl plus 3TC } \\
\text { Patients who received ZDV, } \\
\text { ddl, and 3TC in the ACTG } 302 \\
\text { or } 303 \text { study received only } 1 \\
\text { new nucleoside analogue in } \\
\text { ACTG } 364\end{array}$ \\
\hline
\end{tabular}

Figure 1. Previous Treatment Assignment, Eligibility Criteria, and Treatments of Patients in the AIDS Clinical Trials Group (ACTG) 364 Study.

The 195 patients in the ACTG 364 study had previously undergone randomization and been followed in the ACTG 175 trial as well as in the ACTG 302 study or the ACTG 303 study. ZDV denotes zidovudine, ddl didanosine, ddC zalcitabine, d4T stavudine, 3TC lamivudine, NFV nelfinavir, and EFV efavirenz.

tients with plasma HIV-1 RNA levels of less than 500 copies per milliliter and in terms of the change in the plasma HIV-1 RNA level from base line to week 16. The secondary outcome measures included the long-term effect on HIV-l RNA levels as of weeks 40 and 48 , the time to virologic failure (defined as a confirmed plasma HIV-1 RNA level of at least 2000 copies per milliliter at week 16 or later), and the short- and long-term effects on the CD4 cell count. Adverse events and any newly acquired immunodeficiency syndrome (AIDS)-defining events were graded according to the rating scale of the ACTG. ${ }^{15}$

Patients were recruited from 24 AIDS Clinical Trials Units and 5 regional units of the National Hemophilia Foundation in the United States and Puerto Rico, and they continued to receive their designated nucleoside-analogue therapy until enrollment. None of the patients had previously received a nonnucleoside reverse-transcriptase inhibitor or a protease inhibitor. The study was approved by the institutional review boards of the participating institutions, and all patients provided written informed consent.

The patients were randomly assigned to receive one of three treatments in a double-blind fashion: nelfinavir $(750 \mathrm{mg}$ three times daily), efavirenz (600 $\mathrm{mg}$ once daily), or nelfinavir $(750 \mathrm{mg}$ three times daily) plus efavirenz (600 mg once daily). Each patient was also assigned to receive one of three regimens of open-label nucleoside analogues: didanosine, $200 \mathrm{mg}$ twice daily, plus lamivudine, $150 \mathrm{mg}$ twice daily; didanosine, $200 \mathrm{mg}$ twice daily, plus stavudine, $40 \mathrm{mg}$ twice daily; or stavudine, $40 \mathrm{mg}$ twice daily, plus lamivudine, $150 \mathrm{mg}$ twice daily. These assignments were made on the basis of the treatment the patient had received in the ACTG 302 or 303 study; these regimens were selected so that each patient received at least one and if possible two new nucleoside analogues (Fig. 1). Patients who had received stavudine in a previous ACTG study were assigned to receive didanosine plus lamivudine; those who had received zidovudine plus lamivudine were assigned to receive didanosine plus stavudine; those who had received zidovudine plus didanosine were assigned to receive stavudine plus lamivudine; those who had received zidovudine plus zalcitabine were assigned to receive stavudine plus lamivudine; those who had received zidovudine plus zalcitabine plus lamivudine were assigned to receive didanosine plus stavudine; and those who had received zidovudine plus didanosine plus lamivudine were divided into two groups, one of which was assigned to receive didanosine plus stavudine and the other stavudine plus lamivudine. For patients who weighed less than $60 \mathrm{~kg}$, didanosine was administered in a dose of $125 \mathrm{mg}$ twice daily and stavudine in a dose of $30 \mathrm{mg}$ twice daily.

\section{Monitoring and Enrollment}

Clinical assessments of all patients were performed, their plasma HIV-I RNA levels and CD4 counts were measured, and routine laboratory monitoring was conducted before they entered the study, at the time of entry, at weeks $4,8,12,16$, and 24 , and every 8 weeks thereafter. An executive summary of the week 16 results was released on May 11, 1998; the study was not modified.

\section{Plasma HIV-1 RNA Measurements}

Plasma HIV-1 RNA levels were measured through week 48 with a quantitative assay (Amplicor, Roche Diagnostic) with a lower limit of quantitation of 500 copies per milliliter. Plasma samples that contained fewer than 500 copies per milliliter were retrospectively analyzed with the use of an ultrasensitive assay (Roche Diagnostic) with a lower limit of quantitation of 50 copies per milliliter. 


\section{Genotypic Testing}

Retrospective genotyping was performed on base-line plasma samples from 140 patients with at least one HIV-1 RNA measurement of more than 2000 copies per milliliter. HIV-1 RNA was extracted from plasma, and nested polymerase-chain-reaction amplification was used to generate a $1.3-\mathrm{kb}$ fragment encompassing protease and the first 750 nucleotides of reverse transcriptase. ${ }^{16} \mathrm{Se}-$ quences were compared with the HIV-l clade B consensus sequence (Los Alamos National Laboratory data base), and differences in the amino acid sequence, including positions that contained a mixture of wild-type and mutant residues, were classified as mutations. ${ }^{16-19}$ Phylogenetic analysis of the HIV-l RNA sequence was used to verify the lack of cross-contamination.

\section{Statistical Analysis}

Primary efficacy was assessed on the basis of the plasma HIV-1 RNA level. The means of the values obtained before and at the initiation of study treatment were used as the base-line log-transformed HIV-1 RNA level and CD4 cell count; HIV-1 RNA levels lower than 500 or higher than 750,000 copies per milliliter were replaced by these limits, respectively, before the base-line mean was calculated. If a week 16 measurement of the plasma HIV-1 RNA level or CD 4 cell count was not available, the week 24 or week 12 value was used. Patients with missing values at weeks 12,16 , and 24 or at weeks 40 and 48 were excluded from the analysis of week 16 or weeks 40 and 48 , respectively. The plasma HIV-1 RNA level for weeks 40 and 48 was considered to be at 500 (or 50 by the ultrasensitive assay) copies per milliliter if the HIV-1 RNA level at either week 40 or week 48 was at least 500 (or 50) copies per milliliter. The CD4 cell counts for weeks 40 and 48 were averaged.

Comparisons of the degree of suppression of HIV-1 RNA achieved with the various treatments were performed with tests of proportions, stratified according to the treatment received in the ACTG 302 or 303 study (Cochran-Mantel-Haenszel test). The exact 95 percent confidence intervals for the proportions were computed under the assumption that there would be a binomial distribution. Changes in the CD4 cell count were compared by means of the Kruskal-Wallis test; the 95 percent confidence intervals for the median changes were based on order statistics ${ }^{20}$; the Wilcoxon signed-rank test was used to assess whether the CD4 cell counts had increased from base line. The times to various outcomes were estimated according to the Kaplan-Meier method and compared by means of the stratified log-rank test (stratified according to the treatment received in ACTG 302 or 303). The occurrence of virologic failure was determined on the basis of the time to a confirmed HIV-1 RNA level of at least 2000 (or 200 by the ultrasensitive assay) copies per milliliter at week 16 or later; confirmation was defined as two consecutive measures above the threshold. Data for subjects without virologic failure were censored at the time of the last HIV-1 RNA measurement, at or after week 16. Logisticregression analysis was used to assess the associations between shortterm suppression of HIV-l RNA (at week 16) and long-term suppression (at weeks 40 and 48) and various base-line factors; odds ratios were used to describe the size of the effects. Fisher's exact test was used to compare the proportions from the genotypic analysis. One patient who never received the study treatment and had no follow-up data was excluded from all analyses. The data for the remaining patients, including all available follow-up data through week 52 , were analyzed according to the intention-to-treat principle. Adverse events were evaluated and analyzed through week 56 , but data on adverse events in each patient were censored 8 weeks after the permanent discontinuation of treatment in that patient. P values for pairwise comparisons are two-tailed and are unadjusted for multiple comparisons.

\section{RESULTS}

\section{Enrollment and Base-Line Characteristics}

A total of 196 patients were randomly assigned to treatment groups between July and September 1997.
The patient who did not receive the assigned treatment and for whom no follow-up data were available was excluded from the analyses. Of the remaining 195 patients, 66 were randomly assigned to the nelfinavir group, 65 to the efavirenz group, and 64 to the nelfinavir-plus-efavirenz group. The three treatment groups were well balanced with regard to base-line characteristics (Table 1). Most patients (143 of 195 patients [73 percent]) received two new nucleoside analogues; 52 patients ( 27 percent) who had received zidovudine, didanosine, and lamivudine in the ACTG 302 or 303 study received only one new nucleoside analogue (Fig. 1). The three treatment groups were balanced with regard to the distribution of the assigned regimens of nucleoside analogues at study entry.

\section{Follow-up and Treatment Status}

There was a minimal dropout rate from the study. A total of 11 patients ( 6 percent) had dropped out of the study ( 9 patients) or died ( 2 patients) by week 52 , and the dropout rate did not vary according to treatment group. A total of 33 patients ( 17 percent) permanently discontinued the study treatment during the 52 weeks of follow-up. Most of these patients discontinued treatment because of protocol-defined virologic failure (in 20 patients [61 percent]) or adverse clinical events. The observed rate of permanent discontinuation of the study treatment was 29 percent (19 of 66 patients) in the nelfinavir group, 11 percent ( 7 of 65 patients) in the efavirenz group, and 11 percent ( 7 of 64 patients) in the nelfinavir-plus-efavirenz group ( $\mathrm{P}=0.01$ for the three-way comparison). Virologic failure accounted for the permanent discontinuation of the study drug in 15 of the 19 patients who discontinued treatment in the nelfinavir group (79 percent), 5 of the 7 in the efavirenz group (71 percent), and none of the 7 in the nelfinavir-plusefavirenz group.

\section{Short-Term Effects on Viral Load}

At week 16, the proportions of patients with plasma HIV-1 RNA levels of less than 500 copies per milliliter by the standard assay and less than 50 copies per milliliter by the ultrasensitive assay, respectively, were 81 percent (51 of 63 ) and 67 percent (42 of 63 ) in the nelfinavir-plus-efavirenz group, 69 percent $(45$ of 65 ) and 62 percent ( 40 of 65 ) in the efavirenz group, and 64 percent ( 42 of 66 ) and 39 percent (26 of 66) in the nelfinavir group (Fig. 2). With the quadruple therapy there was a higher rate of suppression of the viral load than with triple therapy with nelfinavir, according to both the standard HIV-1 RNA assay $(\mathrm{P}=0.03)$ and the ultrasensitive assay $(\mathrm{P}=$ $0.001)$; with triple therapy with efavirenz there was a better virologic response than with triple therapy with nelfinavir, according to the ultrasensitive assay $(\mathrm{P}=$ 0.01 ). There was no significant difference between the efavirenz group and the nelfinavir-plus-efavirenz group 
Table 1. Base-Line Characteristics of the Patients.

\begin{tabular}{|c|c|c|c|c|}
\hline Characteristic & $\begin{array}{l}\text { All Patients } \\
(\mathrm{N}=195)\end{array}$ & $\begin{array}{l}\text { NeLFINAVIR } \\
\text { GROUP } \\
(\mathrm{N}=66)\end{array}$ & $\begin{array}{l}\text { EFAVIRENZ } \\
\text { GrouP } \\
(\mathrm{N}=65)\end{array}$ & $\begin{array}{l}\text { NeLFINAVIR- } \\
\text { PLUS-EFAVIRENZ } \\
\text { GROUP } \\
\text { (N=64) }\end{array}$ \\
\hline Male sex — no. (\%) & $171(88)$ & $60(91)$ & $53(82)$ & $58(91)$ \\
\hline Mean age - yr & 41.1 & 39.5 & 43.4 & 40.3 \\
\hline $\begin{array}{l}\text { Race or ethnic group - no. }(\%) \\
\text { Non-Hispanic white } \\
\text { Non-Hispanic black } \\
\text { Hispanic } \\
\text { Asian, Pacific Islander, or other }\end{array}$ & $\begin{aligned} 145 & (74) \\
28 & (14) \\
18 & (9) \\
4 & (2)\end{aligned}$ & $\begin{aligned} 48 & (73) \\
7 & (11) \\
9 & (14) \\
2 & (3)\end{aligned}$ & $\begin{array}{c}46(71) \\
13(20) \\
6(9) \\
-\end{array}$ & $\begin{array}{l}51(80) \\
8(12) \\
3(5) \\
2(3)\end{array}$ \\
\hline Injection-drug use - no. (\%) & $9(5)$ & $3(5)$ & $2(3)$ & $4(6)$ \\
\hline Hemophilia — no. (\%) & $14(7)$ & $5(8)$ & $4(6)$ & $5(8)$ \\
\hline $\begin{array}{l}\text { CD4 cell count }- \text { per } \mathrm{mm}^{3} \\
\text { Median } \\
\text { Range }\end{array}$ & $\begin{array}{l}350 \\
0 \text { to } 1590\end{array}$ & $\begin{array}{l}336 \\
24 \text { to } 935\end{array}$ & $\begin{array}{l}343 \\
0 \text { to } 1004\end{array}$ & $\begin{array}{l}379 \\
42 \text { to } 1590\end{array}$ \\
\hline $\begin{array}{c}\text { Plasma HIV-l RNA level } \\
\text { — copies } / \mathrm{ml}\end{array}$ & & & & \\
\hline $\begin{array}{l}\text { Median } \\
\text { Range }\end{array}$ & $\begin{array}{l}7776 \\
<500 \text { to } \\
>750,000\end{array}$ & $\begin{array}{l}8690 \\
<500 \text { to } \\
>750,000\end{array}$ & $\begin{array}{l}7999 \\
<500 \text { to } \\
421,511\end{array}$ & $\begin{array}{l}5776 \\
<500 \text { to } \\
348,422\end{array}$ \\
\hline $\begin{array}{l}\text { Median duration of previous } \\
\text { nucleoside-analogue treat- } \\
\text { ment }-\mathrm{yr}\end{array}$ & 5.6 & 5.6 & 5.6 & 5.7 \\
\hline
\end{tabular}

in the rate of suppression of HIV-1 RNA at week 16 $(\mathrm{P}=0.11$ with the standard assay and $\mathrm{P}=0.54$ with the ultrasensitive assay).

\section{Long-Term Effects on Viral Load}

The highest rates of response to treatment at weeks 40 and 48 occurred in the nelfinavir-plus-efavirenz group (Fig. 2), in which the rate of suppression of HIV-l RNA was higher than that in the nelfinavir group according to both the standard and the ultrasensitive assays $(\mathrm{P}=0.001$ for both comparisons). Similarly, patients in the efavirenz group had significantly greater reductions of viral load than did those in the nelfinavir group according to both the standard assay $(\mathrm{P}=0.004)$ and the ultrasensitive assay $(\mathrm{P}=0.008)$ (Fig. 2). At weeks 40 and 48, the patients in the nelfinavir-plus-efavirenz group had a higher rate of suppression than those in the efavirenz group according to the ultrasensitive assay $(\mathrm{P}=0.008)$; a similar pattern was seen with the standard assay, but the difference was not statistically significant $(P=0.09)$.

\section{Time to Virologic Failure}

The duration of response, defined as the time from base line to virologic failure (defined as a confirmed plasma HIV-1 RNA level of at least 2000 copies per milliliter according to the standard assay or at least 200 copies per milliliter according to the ultrasensitive assay at week 16 or later) was significantly longer among the patients in the nelfinavir-plus-efavirenz group than among those in the nelfinavir group $(\mathrm{P}<$ 0.001 ) (Fig. 3). By week 48, virologic failure as confirmed by the standard assay had occurred in $30 \mathrm{pa}-$ tients in the nelfinavir group, 20 in the efavirenz group, and 11 in the nelfinavir-plus-efavirenz group; virologic failure as confirmed by the ultrasensitive assay had occurred in 42,27 , and 13 patients, respectively.

\section{Effects on CD4 Cell Count}

A significant increase in the CD4 cell count was sustained, with a median increase from base line to week 16 of 70 cells per cubic millimeter (all groups combined; $\mathrm{P}<0.001 ; 95$ percent confidence interval, 52 to 93 ) and a median increase from base line to weeks 40 and 48 of 94 cells per cubic millimeter $(\mathrm{P}<0.001 ; 95$ percent confidence interval, 80 to 112$)$ (Fig. 4). There were no significant short- or longterm differences in the changes in CD4 cell count among the three treatment groups. Significantly higher median increases in the CD4 cell count at weeks 40 and 48 occurred in patients with HIV-I RNA levels of less than 500 copies per milliliter (a median increase of 113 cells per cubic millimeter) than in those with HIV-1 RNA levels of 500 copies per milliliter or more (a median increase of 66 cells per cubic millimeter $)(\mathrm{P}=0.003)$.

\section{Predictors of Viral Suppression at Weeks $\mathbf{4 0}$ and 48}

Multivariate logistic-regression models were constructed in which the patients were recategorized ac- 
A

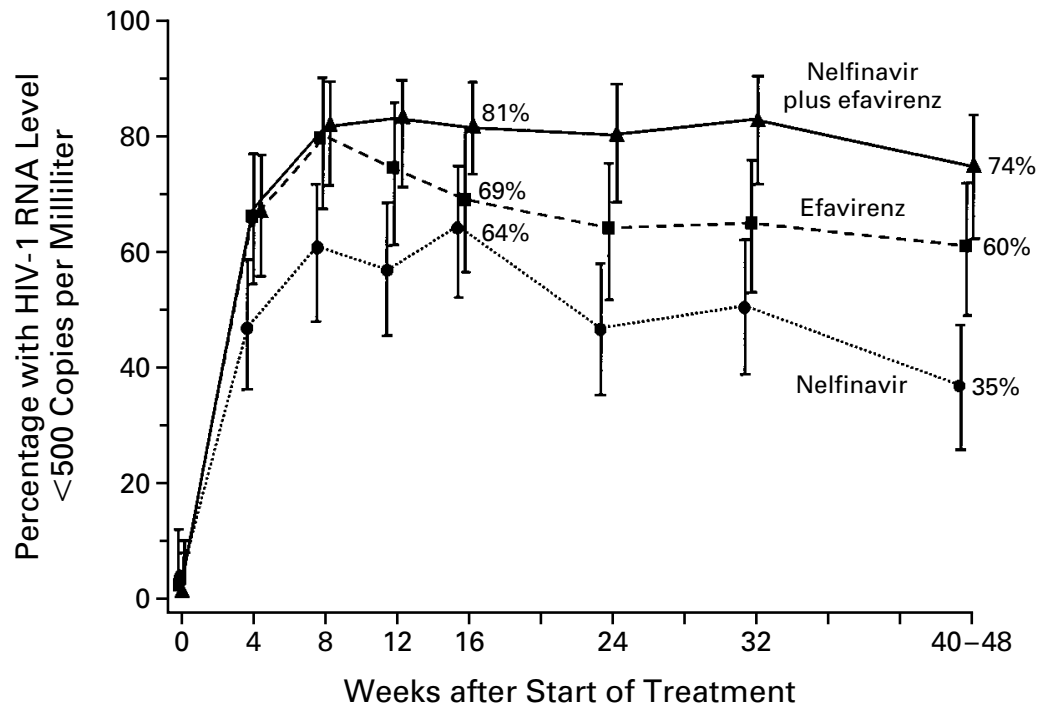

No. of PATIENTS

$\begin{array}{lllllllll}\text { Nelfinavir } & 66 & 66 & 60 & 65 & 66 & 65 & 64 & 65 \\ \text { Efavirenz } & 65 & 65 & 64 & 65 & 65 & 61 & 62 & 63 \\ \text { Nelfinavir plus } & 63 & 60 & 62 & 60 & 63 & 59 & 61 & 61\end{array}$
efavirenz

B

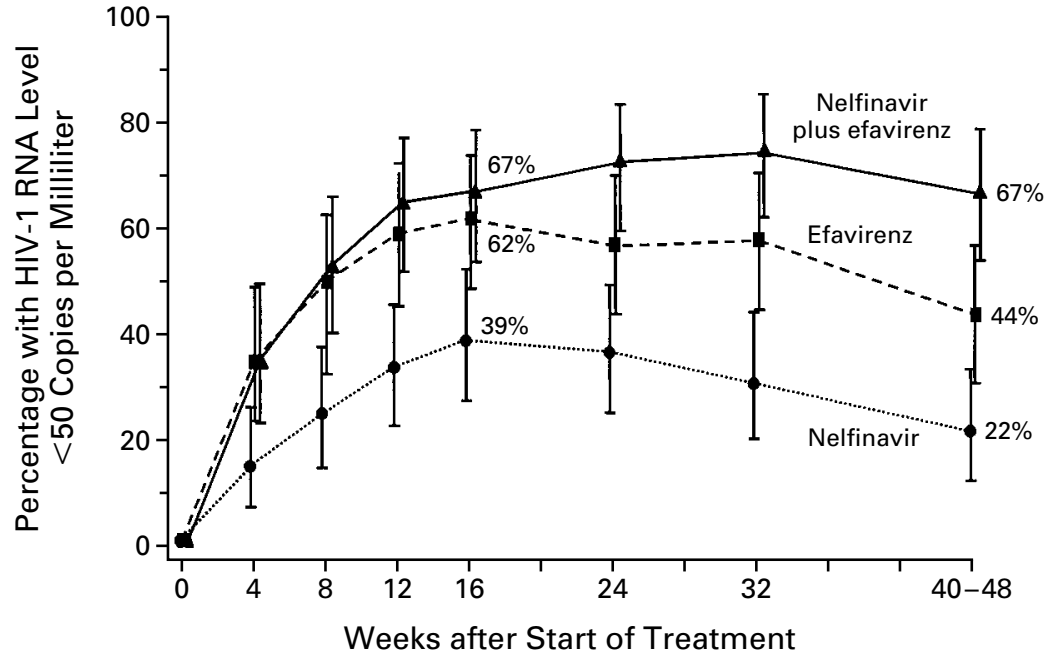

No. of PATIENTS

$\begin{array}{llllllll}\text { Nelfinavir } & 66 & 60 & 64 & 66 & 65 & 64 & 65 \\ \text { Efavirenz } & 65 & 64 & 65 & 65 & 61 & 62 & 62 \\ \text { Nelfinavir plus } & 60 & 62 & 60 & 63 & 59 & 60 & 61 \\ \quad \text { efavirenz } & & & & & & \end{array}$

Figure 2. Percentage of Patients with Plasma HIV-1 RNA Levels of Less Than 500 Copies per Milliliter According to the Standard Assay (Panel A) and Less Than 50 Copies per Milliliter According to the Ultrasensitive Assay (Panel B).

I bars represent the 95 percent confidence intervals. 
A
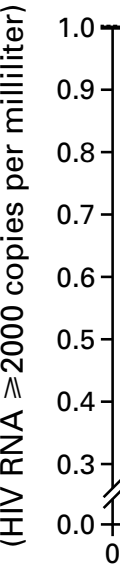

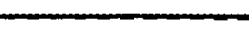

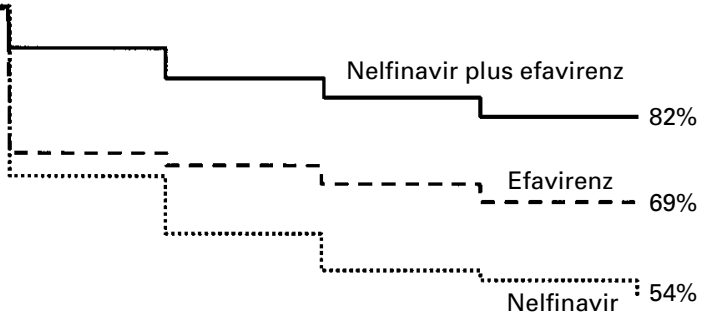

No. AT RISK

Nelfinavir

Efavirenz

Nelfinavir plus

efavirenz

66
65
64

65

63

62

47

48

57

24

32

40

B

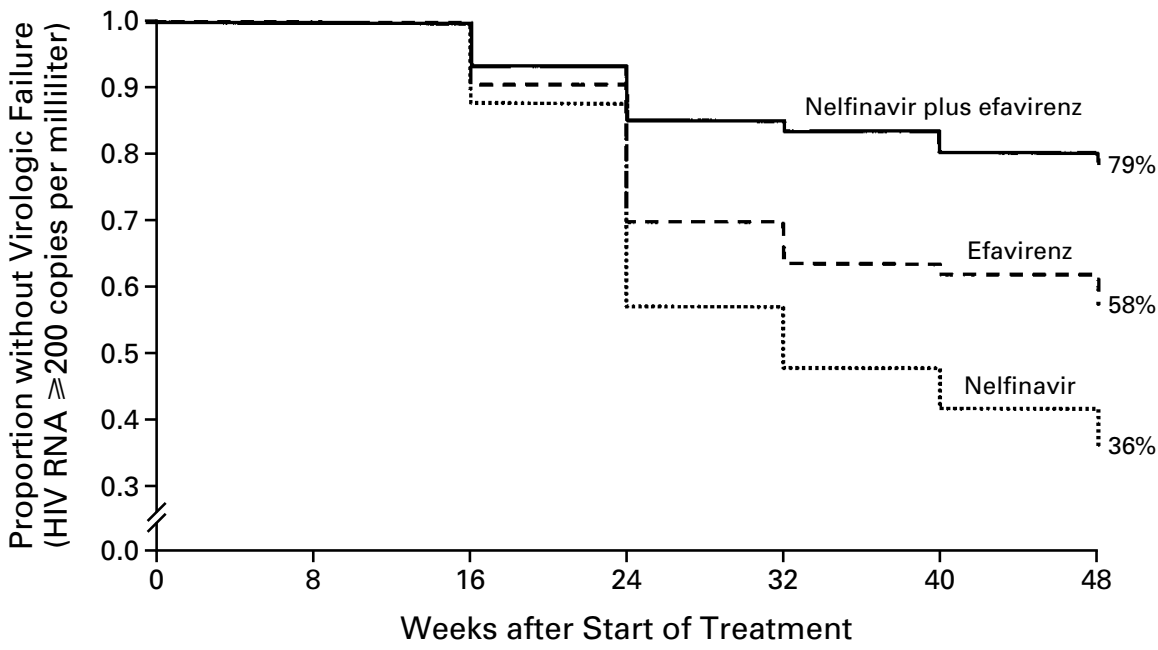

No. AT RISK

Nelfinavir

Efavirenz

Nelfinavir plus

efavirenz

$\begin{array}{lllll}65 & 57 & 37 & 31 & 27 \\ 64 & 57 & 44 & 40 & 39 \\ 62 & 57 & 52 & 51 & 48\end{array}$

$\begin{array}{cc}\text { No. FOR WhOM } & \text { No. With } \\ \text { DATA CENSORED } & \text { FAILURE } \\ 36 & 30 \\ 45 & 20 \\ 53 & 11\end{array}$

Figure 3. Kaplan-Meier Estimates of the Time to Virologic Failure.

Virologic failure was defined as a plasma HIV-1 RNA level of at least 2000 copies per milliliter according to the standard assay (Panel A) and at least 200 copies per milliliter according to the ultrasensitive assay (Panel B). In Panel A, the stratified log-rank P values were as follows: 0.14 for the comparison of nelfinavir with efavirenz, $<0.001$ for the comparison of nelfinavir with nelfinavir plus efavirenz, and 0.06 for the comparison of efavirenz with nelfinavir plus efavirenz. In Panel B, the stratified log-rank $\mathrm{P}$ values were as follows: 0.04 for the comparison of nelfinavir with efavirenz, $<0.001$ for the comparison of nelfinavir with nelfinavir plus efavirenz, and 0.01 for the comparison of efavirenz with nelfinavir plus efavirenz. 
cording to whether they received lamivudine for the first time in the ACTG 364 study. The base-line HIV-l RNA level $(\mathrm{P}<0.001)$, treatment with lamivudine as a new nucleoside analogue $(\mathrm{P}<0.001)$, and the treatment assignment in the current trial $(\mathrm{P}<$ 0.001 ) were significant independent predictors of viral suppression (defined as an HIV-1 RNA level of less than 500 copies per milliliter and less than 50 copies per milliliter according to the two different assays) at weeks 40 and 48 (Table 2). Early decreases in the plasma HIV-l RNA level were evaluated to determine whether they were predictive of the changes in viral load at weeks 40 and 48 . After adjustment for treatment assignment, an HIV-I RNA level of less than 50 copies per milliliter at week 16 was highly predictive of viral suppression at weeks 40 and 48 $(\mathrm{P}<0.001$; odds ratio, 9.77; 95 percent confidence interval, 4.63 to 22.19 ).

\section{Base-Line Genotypic Mutations and Virologic Outcome}

Previous exposure to drugs and mutations in the reverse-transcriptase gene at base line were examined retrospectively in 140 patients with available base-line genotypic data. High-level resistance to nucleoside reverse-transcriptase inhibitors was defined by the presence of five or more of the specified reverse-transcriptase mutations or a mutation or insertion known to confer multinucleoside resistance (Table 3).

Among the patients in whom genotyping was completed, the response rates within the treatment groups at weeks 40 and 48 were similar to those in the overall study population. In the group with five or more reverse-transcriptase mutations or a known genetic marker of multinucleoside resistance at base line, HIV-1 RNA levels of less than 50 copies per milliliter were achieved at weeks 40 and 48 in 19 percent of the patients in the nelfinavir group (4 of 21) and 30 percent of those in the efavirenz group ( 3 of 10 ), as compared with 75 percent of the patients in the nelfinavir-plus-efavirenz group (9 of 12) (Table 3 ). There was a significant difference between the nelfinavir group and the nelfinavir-plus-efavirenz group in long-term viral suppression among patients with high-level reverse-transcriptase resistance $(\mathrm{P}=0.003)$, and there was a trend toward significance in the difference between the efavirenz group and the nelfinavir-plus-efavirenz group $(\mathrm{P}=0.08)$.

\section{Adverse Events and Clinical Disease Progression}

There was no significant difference among the three treatment groups with respect to the time to the development of the first grade 3 (severe) or grade 4 (lifethreatening) signs or symptoms, which occurred in a total of 36 patients (18 percent) -12 patients in the nelfinavir group, 10 in the efavirenz group, and 14 in the nelfinavir-plus-efavirenz group ( $\mathrm{P}>0.3$ for all pairwise comparisons). The most frequent grade 3 or 4 signs or symptoms reported were aches, pain, or discomfort (in 13 patients [7 percent]) and diarrhea or loose stools (in 7 patients [ 4 percent]). A grade 3

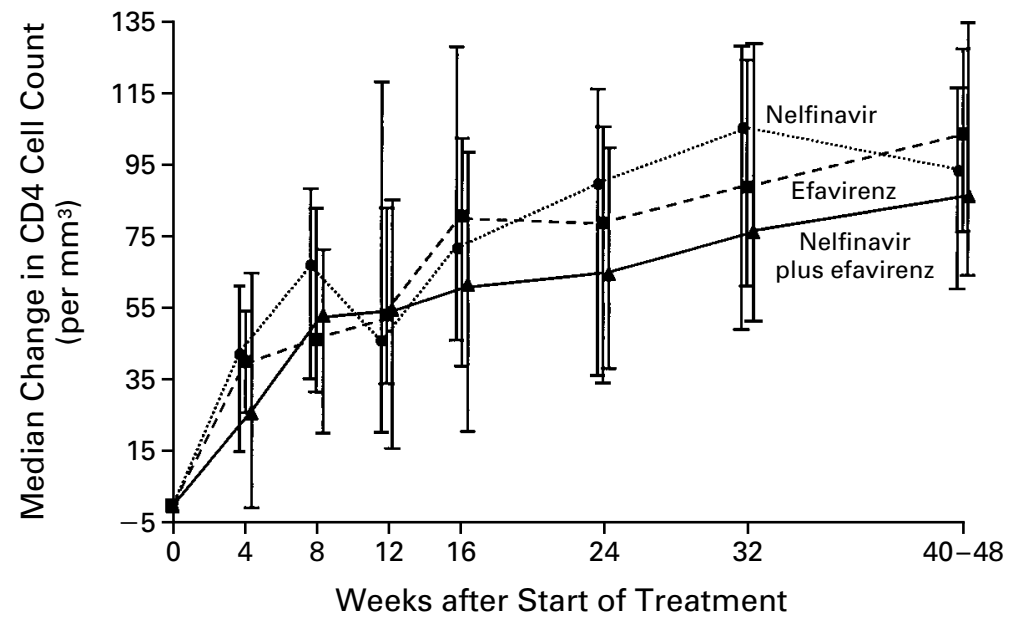

No. OF PATIENTS

$\begin{array}{lllllllll}\text { Nelfinavir } & 66 & 65 & 63 & 64 & 66 & 65 & 64 & 65 \\ \text { Efavirenz } & 65 & 65 & 63 & 64 & 65 & 64 & 61 & 63 \\ \begin{array}{l}\text { Nelfinavir plus } \\ \text { efavirenz }\end{array} & 64 & 60 & 63 & 62 & 63 & 62 & 62 & 61\end{array}$

Figure 4. Median Changes in CD4 Cell Count from Base Line. I bars represent the 95 percent confidence intervals. 
Table 2. Base-Line Predictors of Viral Suppression at Weeks 40 and 48 in Multivariate Analysis.*

\begin{tabular}{|c|c|c|c|c|}
\hline BASE-LINE FACTOR & $\begin{array}{c}\text { HIV-1 RNA } \\
<500 \text { coPIES } / \mathrm{ml} \\
\text { odds ratio }(95 \% \mathrm{Cl})\end{array}$ & P Value & $\begin{array}{c}\text { HIV-1 RNA } \\
<50 \text { coPIEs } / \mathrm{ml} \\
\text { odds ratio }(95 \% \mathrm{Cl})\end{array}$ & P Value \\
\hline $\begin{array}{l}\text { Treatment } \\
\text { Nelfinavir } \\
\text { Efavirenz } \\
\text { Nelfinavir plus efavirenz }\end{array}$ & $\begin{array}{l}0.15(0.06-0.35) \\
0.50(0.21-1.17) \\
1.00\end{array}$ & $<0.001$ & $\begin{array}{l}0.12(0.05-0.27) \\
0.34(0.15-0.74) \\
1.00\end{array}$ & $<0.001$ \\
\hline $\begin{array}{l}\text { HIV-1 RNA level (per } \log _{10} \\
\text { decrease) }\end{array}$ & $3.21(2.00-5.41)$ & $<0.001$ & $2.30(1.47-3.73)$ & $<0.001$ \\
\hline $\begin{array}{l}\text { Lamivudine as new nucleoside } \\
\text { analogue at study entry }\end{array}$ & $7.40(3.34-17.72)$ & $<0.001$ & $3.34(1.64-7.04)$ & $<0.001$ \\
\hline
\end{tabular}

${ }^{*} \mathrm{CI}$ denotes confidence interval.

Table 3. Base-Line Genotypic Mutations and Viral Suppression AT WeEKS 40 AND 48 .* $^{*}$

\begin{tabular}{|c|c|c|c|}
\hline \multirow[t]{2}{*}{ TREATMENT } & $\begin{array}{c}\text { AlL PATIENTS } \\
\text { WITH GenOtYPIC } \\
\text { DATA }\end{array}$ & $\begin{array}{c}\text { PATIENTS WITH 0-4 } \\
\text { RT MUTATIONS AND } \\
\text { No KNOWN GENETIC } \\
\text { MARKER OF MNR }\end{array}$ & $\begin{array}{c}\text { PATIENTS WITH } 5 \text { OR } \\
\text { MORE RT MUTATIONS } \\
\text { OR A KNOWN GENETIC } \\
\text { MARKER OF MNR }\end{array}$ \\
\hline & \multicolumn{3}{|c|}{ no. with suppression/total no. with genotypic data (\%) } \\
\hline Nelfinavir & $11 / 51(22)$ & $7 / 30(23)$ & $4 / 21(19)$ \\
\hline Efavirenz & $17 / 46(37)$ & $14 / 36(39)$ & $3 / 10(30)$ \\
\hline Nelfinavir plus efavirenz & $27 / 43(63)$ & $18 / 31(58)$ & $9 / 12(75)$ \\
\hline
\end{tabular}

*Viral suppression was defined as a plasma HIV-1 RNA level of less than 50 copies per milliliter according to the ultrasensitive assay. Nucleoside reverse-transcriptase mutations at codons $41,65,67$, $69,70,74,75,184,210,215$, and 219 were considered evidence of resistance to nucleoside reversetranscriptase (RT) inhibitors. ${ }^{17}$ Patients were considered to have high-level resistance if they had five or more of these cardinal mutations or if they had one of the following known markers of multinucleoside resistance (MNR): a Q151M mutation in the RT gene, accompanied by A62V, V75I, F77L, and F116Y mutations, or an amino acid insertion at codon 69.17 Six sequences with MNR had an insertion at codon 69. These mutations are present in fewer than 1 percent of the sequences obtained from persons who have not been treated with antiretroviral drugs, are associated with in vitro resistance, and occur among patients in whom combination antiretroviral therapy has failed. ${ }^{17-19}$

or 4 rash developed in only three patients $(2$ percent). Grade 2 (moderate) peripheral neuropathy developed in six patients ( 3 percent).

There were no significant differences among the three treatment groups in the time to development of grade 3 or 4 laboratory abnormalities, which occurred in a total of 58 patients $(30$ percent $)-23$ patients in the nelfinavir group, 17 in the efavirenz group, and 18 in the nelfinavir-plus-efavirenz group $(\mathrm{P}>0.3$ for all pairwise comparisons). The most common laboratory abnormalities were creatine kinase elevations (in 23 patients [ 12 percent]) and elevated triglyceride levels (in 21 patients [ 11 percent]).

During 52 weeks of follow-up, an AIDS-defining lymphoma developed in one patient in the nelfinavirplus-efavirenz group ( 3 weeks after the study treatment began). Two patients (one in the nelfinavir group and one in the efavirenz group) died, but their deaths were not attributed to HIV infection.

\section{DISCUSSION}

We found that in HIV-infected patients who have previously undergone prolonged therapy with nucleoside analogues, quadruple therapy with nelfinavir, efavirenz, and two nucleoside analogues, of which at least one was new, achieved higher rates of viral suppression (a plasma HIV-1 RNA level of less than 50 copies per milliliter) at weeks 40 and 48 and signif- 
icantly more durable suppression, measured in terms of time to failure (a confirmed plasma HIV-1 RNA level of at least 200 copies per milliliter), than triple therapy with either nelfinavir or efavirenz and new nucleoside analogues. The response rates in the nelfinavir-plus-efavirenz group were similar to those reported in the DMP 266-020 study ${ }^{21}$ and a pediatric clinical trial ${ }^{22}$ that evaluated efavirenz in combination with a protease inhibitor plus nucleoside analogues in patients who had previously been treated with nucleoside analogues.

Triple therapy with efavirenz conferred greater and more durable viral suppression than triple therapy with nelfinavir. We cannot fully explain the inferior viral suppression observed in the nelfinavir group as compared with the nelfinavir-plus-efavirenz group and the efavirenz group in this study. In the subgroup in whom genotyping was performed, there were similarly low rates of viral suppression in those with zero to four reverse-transcriptase mutations ( 23 percent of the nelfinavir group) as in those with five or more reverse-transcriptase mutations at base line or the presence of mutations known to confer multinucleoside resistance (19 percent of the nelfinavir group). The distribution of reverse-transcriptase genotypes in this subgroup does not fully explain the inferior virologic outcomes in the nelfinavir group, since the response rate found in each treatment group in the subgroup analysis was similar to that found in that treatment group in the primary analysis of the entire study population.

The pharmacokinetic profiles of the study drugs and adherence to the treatment regimens were not evaluated in this study, which precludes any assessment of whether adequate exposure to nelfinavir was achieved in this population of patients. The patients in the nelfinavir group had CD4 cell responses that were similar to those observed in the other two groups, which suggests that partially suppressive regimens in patients who have already undergone treatment with nucleoside analogues may still confer clinical benefit by affording substantial increases in the CD4 cell count.

Extensive previous treatment with nucleoside analogues that has led to the development of mutations associated with resistance to zidovudine may result in hypersusceptibility to nonnucleoside reversetranscriptase inhibitors. ${ }^{23,24}$ This phenomenon was observed in a preliminary phenotypic analysis conducted at base line in 130 patients in the present study: 37 percent of isolates of virus from these patients were hypersusceptible to efavirenz (i.e., the concentration required to inhibit viral replication by 50 percent $\left[\mathrm{IC}_{50}\right]$ was $<0.4$ of the $\mathrm{IC}_{50}$ for a wild-type reference strain). Although hypersusceptibility to nonnucleoside reverse-transcriptase inhibitors at base line was not found to be highly predictive of long-term viral suppression in our exploratory analyses, the continued use of nucleoside analogues to maintain hypersuscepti- bility in salvage regimens may be a treatment strategy that warrants further evaluation.

Although we did not prospectively evaluate genotyping at base line, patients who have been extensively exposed to nucleoside analogues and who have viral rebound may benefit from genotyping if two new classes of drugs are introduced when nucleoside resistance is confirmed. Although conserving some classes of treatment for later use is an important consideration in patients in whom virologic failure has occurred once or twice, the selection of inadequately potent and partially suppressive alternative regimens may result in the evolution of drug resistance in blood and other tissue compartments. The benefits of using additional classes of potent agents, as we did in the nelfinavir-plus-efavirenz group, with the goal of suppressing viral replication to below the limit of detection and of restoring the immune response must be weighed against the potential risks of incurring new or long-term toxic effects and limiting future treatment options.

Supported by the AIDS Clinical Trials Group, National Institute of Allergy and Infectious Diseases (grants U01 Al27659, AI-25924, AI-27664, and AI-27660), and the General Clinical Research Center units funded by the National Center for Research Resources; by Agouron Pharmaceuticals (which also provided nelfinavir), Dupont Pharmaceuticals (which also provided efavirenz), Glaxo Wellcome (which also provided zidovudine, lamivudine, and Combivir), and Bristol-Myers Squibb (which also provided didanosine and stavudine); and by the Statistical and Data Analysis Center, Harvard School of Public Health (grant 5 U01 Al38855).

We are indebted to the following persons who contributed to the overall study design and the interpretation of the end-point analyses and provided critical commentary on the manuscript: Mark Becker, Pharm.D., Agouron Pharmaceuticals; Michael Stevens, Pharm.D., Bristol-Myers Squibb; Nancy M. Ruiz, M.D., and Douglas J. Manion, M.D., Dupont Pharmaceuticals; and Alex R. Rinehart, Ph.D., and S. Diane Goodwin, Pharm.D., Glaxo Wellcome.

\section{APPENDIX}

In addition to the authors, the following institutions and persons participated in the ACTG 364 study: C. Delaney, C. Crumpacker (Harvard University); J. Drury (Northwestern University Medical School); C.A. Leissinger (National Hemophilia Foundation); M.F. Para, C. Jackson (Ohio State University College of Medicine and Public Health; AIDS Clinical Trials Unit grant AI-25924); D. Slamowitz, P. Cain (Stanford University); A. Conrad, G. Gagliono (Case Western Reserve University); D. Ragan (University of North Carolina); M. Klebert, P. Tebas (Washington University); R.L. Becker, M.J. Higgins (Johns Hopkins University); D. Davis, M. Saag (University of Alabama); M.A. Fischl, E. Scerpella (University of Miami); H. Balfour (University of Minnesota); K. Sepkowitz, L. Ponticello (Cornell University); K. Dybeck, D. Abrams (University of California, San Francisco); B. Simpson, H. Mendoza (Mt. Sinai Medical Center); P.T. Frame, D. Neumann (University of Cincinnati); J.L. Santana, G.J. Vazquez (University of Puerto Rico); G. Casey, M. Borucki (University of Texas, Galveston); K. Fife, B. Zwickl (Indiana University); A.C. Collier, B.A. Royer (University of Washington, Seattle; AIDS Clinical Trials Unit grant AI-27664); R. Schooley (University of Colorado Health Sciences Center); M. Carlson, A. Johiro (University of California, Los Angeles); J. Reid, M. Lewis (University of Rochester); I. Frank, I. Matozzo (University of Pennsylvania); J. Forcht, V. Rosenwald (New York University); Statistical and Data Analysis Center, Harvard School of Public Health.

\section{REFERENCES}

1. Carpenter CC, Fischl MA, Hammer SM, et al. Antiretroviral therapy for HIV infection in 1998: updated recommendations of the International AIDS Society-USA Panel. JAMA 1998;280:78-86. 
2. Report of the NIH Panel to Define Principles of Therapy of HIV Infection. MMWR Morb Mortal Wkly Rep 1998;47(RR-5):1-41.

3. Gulick RM, Mellors JW, Havlir D, et al. Treatment with indinavir, zidovudine, and lamivudine in adults with human immunodeficiency virus infection and prior antiretroviral therapy. N Engl J Med 1997;337:734-9. 4. Hammer SM, Squires KE, Hughes MD, et al. A controlled trial of two nucleoside analogues plus indinavir in persons with human immunodeficiency virus infection and CD4 cell counts of 200 per cubic millimeter or less. N Engl J Med 1997;337:725-33

5. Kempf DJ, Rode RA, Xu Y, et al. The duration of viral suppression during protease inhibitor therapy for HIV-l infection is predicted by plasma HIV-1 RNA at the nadir. AIDS 1998;12:F9-F14.

6. Palella FJ Jr, Delaney KM, Moorman AC, et al. Declining morbidity and mortality among patients with advanced human immunodeficiency virus infection. N Engl J Med 1998;338:853-60.

7. Hogg RS, Heath KV, Yip B, et al. Improved survival among HIVinfected individuals following initiation of antiretroviral therapy. JAMA 1998;279:450-4

8. Montaner JSG, Reiss P, Cooper D, et al. A randomized, double-blind trial comparing combinations of nevirapine, didanosine, and zidovudine for HIV-infected patients: the INCAS Trial. JAMA 1998;279:930-7.

9. Staszewski S, Morales-Ramirez J, Tashima KT, et al. Efavirenz plus zidovudine and lamivudine, efavirenz plus indinavir, and indinavir plus zidovudine and lamivudine in the treatment of HIV-l infection in adults. N Engl J Med 1999;341:1865-73.

10. Staszewski S, Morales-Ramirez JO, Godofsky EW, et al. Longer time to treatment failure and durability of response with efavirenz $+\mathrm{ZDV}+3 \mathrm{TC}$ first analysis of full 1266 patient cohort from study 006. In: Program and abstracts of the 39th Interscience Conference on Antimicrobial Agents and Chemotherapy, San Francisco, September 26-29, 1999. Washington, D.C.: American Society for Microbiology, 1999:473. abstract.

11. Hirsch M, Steigbigel R, Staszewski S, et al. A randomized, controlled trial of indinavir, zidovudine, and lamivudine in adults with advanced human immunodeficiency virus type 1 infection and prior antiretroviral therapy. J Infect Dis 1999;180:659-65.

12. Katzenstein DA, Hughes M, Albrecht M, et al. Virologic and CD4+ cell responses to new nucleoside regimens: switching to stavudine or adding lamivudine after prolonged zidovudine treatment of human immunodeficiency virus infection. AIDS Res Hum Retroviruses 2000;16:1031-

13. Albrecht MA, Hughes MD, Liou SH, et al. The effect of lamivudine in HIV infected persons with prior exposure to zidovudine/didanosine or zidovudine/zalcitabine. AIDS Res Hum Retroviruses 2000;16:1337-44.

14. Hammer SM, Katzenstein DA, Hughes MD, et al. A trial comparing nucleoside monotherapy with combination therapy in HIV-infected adults with CD4 cell counts from 200 to 500 per cubic millimeter. N Engl J Med 1996;335:1081-90.
15. Division of AIDS. Division of AIDS table for grading severity of adult adverse experiences. Rockville, Md.: National Institute of Allergy and Infectious Diseases, 1996.

16. Winters MA, Schapiro JM, Lawrence J, Merigan TC. Human immunodeficiency virus type 1 protease genotypes and in vitro protease inhibitor susceptibilities of isolates from individuals who were switched to other protease inhibitors after long-term saquinavir treatment. J Virol 1998;72: 5303-6.

17. DeGruttola V, Dix L, D'Aquila R, et al. The relation between baseline HIV drug resistance and response to antiretroviral therapy: re-analysis of retrospective and prospective studies using a standardized data analysis plan. Antivir Ther 2000;5:41-8.

18. Hammond J, Calef C, Larder B, Schinazi R, Mellors JW. Mutations in retroviral genes associated with drug resistance. In: Kuiken C, Foley B, Hahn B, et al., eds. Human retroviruses and AIDS: a compilation and analysis of nucleic acid and amino acid sequences. Los Alamos, N.M.: The oretical Biology and Physics, Los Alamos National Laboratory, 1999:542 91.

19. Hirsch MS, Conway B, D'Aquila RT, et al. Antiretroviral drug resistance testing in adults with HIV infection: implications for clinical management. JAMA 1998;279:1984-91.

20. Zar JH. Biostatistical analysis. 2nd ed. Englewood Cliffs, N.J.: Prentice-Hall, 1984:390

21. Haas DW, Fessel WJ, Delapenha A, et al. A phase II, double-blind, placebo-controlled multicenter study to evaluate the effectiveness and tolerability of the combination of efavirenz (EFV, Sustiva, DMP-266) and indinavir (IDV) in HIV-l infected patients receiving nucleoside analogue therapy (NRTI) at $>36$ weeks. In: Program and abstracts of the 38th Interscience Conference on Antimicrobial Agents and Chemotherapy, San Diego, Calif., September 24-27, 1998. Washington, D.C.: American Society for Microbiology, 1998:441. abstract.

22. Starr SE, Fletcher CV, Spector SA, et al. Combination therapy with efavirenz, nelfinavir, and nucleoside reverse-transcriptase inhibitors in children infected with human immunodeficiency virus type 1 . N Engl J Med 1999;341:1874-81.

23. Haubrich R, Whitcomb J, Keiser P, et al. Non-nucleoside reverse transcriptase inhibitor viral hypersensitivity is common and improves shortterm virological response. Antivir Ther 2000;5:Suppl 3:69. abstract.

24. Katzenstein D, Hellmann N, Liou S, Bosch R, Albrecht M, ACTG 364 Study Team. Phenotypic susceptibility and virologic responses in nucleoside reverse transcriptase inhibitor (NRTI)-experienced subjects receiving NRTIs + efavirenz (EFV), nelfinavir (NFV), or both in ACTG 364

In: Program and abstracts of the Eighth Conference on Retroviruses and Opportunistic Infections, Chicago, February 4-8, 2001:172. abstract.

Copyright (C) 2001 Massachusetts Medical Society. 